\title{
Isla de cenizas. Crítica social de la injusticia ${ }^{1}$
}

\author{
Katherine Mansilla Torres \\ Pontificia Universidad Católica del Perú
}

\section{Resumen:}

Este ensayo parte de un caso de injusticia social ocurrido en julio de 2017 -el incendio de la galería comercial Nicolini en las Malvinas de Lima- para analizar y reconocer elementos constituyentes de injusticias estructurales: historicidad, prejuicios, dinámicas excluyentes del mercado económico y menosprecio social. Con todo ello, se busca reflexionar sobre prácticas de injusticia que se insertan anónimamente en las relaciones sociales y en la vida académica, lo cual impide hacer una crítica o una revisión de posturas éticas y políticas para alcanzar nuevas comprensiones de escenarios sociales, los cuales continúan definiéndose y articulándose con el Estado desde aspectos negativos. El ensayo toma en cuenta las reflexiones teóricas de Michel Polanyi, Miranda Fricker y Axel Honneth, y propone una reflexión final que permita desarrollar nuevas interpretaciones sobre escenarios típicos de injusticia estructural.

Palabras clave: injusticia, mercado capitalista, intersubjetividad, menosprecio, Las Malvinas, informalidad, Fricker, Polanyi, Honneth.

\begin{abstract}
:
This essay is based in a case of social injustice that occurred in July 2017 -the fire of the Nicolini gallery in the Malvinas de Lima. We want to analyze and recognize constitutives elements of structural injustices: historicity, prejudices, dynamics of exclusion in the economic market and social disparagement. We reflect on the practices of injustice that are inserted in social relationships and in academic life anonymously, which these prevents making a criticism or a review of ethical and political positions to reach new understandings of social scenarios that are still defined and articulating to the State from negative aspects. The essay considers the theoretical reflections of Michel Polanyi,
\end{abstract}

1 Una versión inicial de este trabajo fue presentada en el XVI Simposio Filosófico que se realizó en el Instituto Superior de Estudios Teológicos Juan XXIII los días 27,28 y 29 de mayo de 2019. 
Miranda Fricker, and Axel Honneth, and proposes a final reflection that allows developing new interpretations on typical scenarios of structural injustice.

Key Words: injustice, capitalist market, intersubjetivity, disparagement, Las Malvinas, informalidad, Fricker, Polanyi, Honneth.

\section{Introducción}

El 23 de junio de 2017, la Galería Nicolini, ubicada en lo que antes se conoció como el campo ferial "Las Malvinas" del Cercado de Lima, sufrió un brutal incendio en grado cinco. Se necesitaron siete días para extinguir el fuego y diez días más para entrar al edificio; se produjeron alrededor de ocho millones de pérdidas económicas, hubo 89 heridos y dos muertos (Gestión, 2017). El entonces presidente, Pedro Pablo Kuczynski, en su visita al lugar de la tragedia, se refirió a la necesidad de una acción judicial para procesar a los culpables de lo que llamó un "terrible acto criminal" (Guzmán, 2017). Representantes de la Municipalidad de Lima declararon que tanto la galería incendiada, como muchas otras de la zona eran una "bomba de tiempo": almacenes llenos de cables, plásticos, pinturas, disolventes; todo era considerado de alto riesgo de inflamación, razón por la cual, semanas antes, habían suspendido, a través de un simple comunicado, el funcionamiento de sus pisos altos.

No obstante, el origen del incendio revelaba un problema más complejo que un "acto criminal" que podría ser resuelto en el fuero judicial. El incendio sacaba a la luz una historia compleja de progreso y poder. Vimos cómo dos jóvenes, Jorge Luis Huamán (19 años) y Yovi Herrera (20 años), quienes trabajaban en la galería, estaban atrapados en almacenes ilegales precariamente fabricados con containers. Desde ahí, ellos lanzaban fluorescentes y tubos de policloruro de vinilo (PVC) para pedir auxilio a los bomberos, quienes nunca pudieron acudir a su rescate. Yonny Coico, jefe de los jóvenes y dueño de uno de los puestos comerciales, los había encerrado con candado en el container donde trabajaban. Tanto para el empleador como para los empleados, 
el encierro era parte indubitable de su jornada de trabajo de 12 horas: los jóvenes comían y excretaban ahí, mientras borraban la marca de los fluorescentes y colocaban otra marca de más valor en el mercado ferretero. Encerrarlos era la estrategia para que no se robaran nada.

En la prensa, el tema del “incendio de Las Malvinas" ocupó columnas y editoriales solamente dos meses, y -en la mayoría de los casos- no se brindó información seria sobre la situación laboral de la también llamada "esclavitud moderna", es decir, la cantidad de jóvenes que, en pleno siglo XXI, se desempeñan en trabajos informales y precarios. Los comentarios en redes sociales eran una lista de adjetivos y prejuicios sobre el lugar: "zona brava", "delincuentes", "ignorancia”, "sin educación”. Sobre Las Malvinas, tampoco se pronunció la academia ni la sociedad civil se organizó para agendar la terrible la situación del trabajo precario juvenil.

He nacido en el barrio de Las Malvinas y he pasado gran parte de mi vida ahí, razón por la que me interesa ensayar una reflexión sobre la injusticia, desde mi experiencia personal y mis intereses académicos, que revele una situación concreta de injusticia para reflexionar sobre las relaciones de poder y exclusión social que se entretejen en una zona comercial como esta. Pienso que esta realidad ejemplifica no una situación crítica en particular, sino una historia social de injusticia que aparece como en una dimensión tácita con la que nos hemos acostumbrado a vivir, una situación que se expande silenciosamente en el tiempo y reafirma injusticias sociales, económicas y culturales que se traslapan entre sí y terminan por multiplicar sus formas de exclusión. Divido mi argumentación en tres partes. En la primera, presento cierta información sobre la constitución de Las Malvinas como espacio económico y social ejemplar de formas de injusticia histórica. En la segunda parte, analizo por qué el caso expresa un cierto tipo de injusticias persistentes, para lo cual me apoyo en las reflexiones de M. Polanyi, M. Fricker y A. Honneth. En la tercera parte, ensayo ciertas ideas que podrían cambiar una forma de pensar situaciones o escenarios de informalidad social. 


\section{Breve génesis de la isla}

Si bien existe amplia literatura sobre el desarrollo del comercio ambulatorio en Lima (Grompone, 1999; Granados, 1997; Cosamalón, 2018; entre otros), no se cuenta con un trabajo específico sobre el Campo Ferial Las Malvinas y su desarrollo ulterior, por lo que me permito reconstruir esta parte desde mis recuerdos como vecina de la zona. Entre 1950 y 1970, las industrias madereras, ferreteras, metalúrgicas e incluso de alimentos se instalaron a lo largo de la Av. Argentina, la cual terminó por convertirse en una importante zona industrial de la capital. Algunas empresas exitosas (por ejemplo, la maderera Ostolaza o la fábrica Singer) construyeron a su alrededor pequeńas viviendas para sus trabajadores. Mientras más se desarrollaba la industria, había más oportunidades de empleo, por lo que los obreros decidieron alquilar pequeños cuartos en solares viejos cerca de las fábricas o tomar terrenos inhabilitados para que los sueldos pudieran compensar sus gastos. Posteriormente, como explican Contreras y Cueto (2007), el crecimiento poblacional y la migración del campo a la ciudad, motivada por mejorar las condiciones de vida y los accesos a servicios, cambió la composición urbana de la zona. Los terrenos baldíos se convirtieron en quintas, callejones y barriadas en las que vivían nuevos obreros. A inicios de los ańos ochenta, el pequeño comercio ambulatorio instalado en la plaza Ramón Castilla y Dos de Mayo aumentó, debido a los desalojos de ambulantes del Centro Histórico. Así, por ejemplo, entre las cuadras 6 y 7 de la Av. Argentina, se instaló una "paradita" de comerciantes de abarrotes y artículos de primera necesidad que, en la mayoría de los casos, eran migrantes de la Sierra central que asistían la vida diaria de los obreros vecinos. Los barrios instalados entre la Av. Colonial y la Argentina se tugurizaban por nuevos vecinos que llegaban a vivir con el inmenso entusiasmo por el acceso a oportunidades laborales. Como ha señalado Matos Mar (1984, 1991), se establecía una dinámica cultural y social a través de un sector informal que permitía el desarrollo de nuevos campos comerciales y laborales: los nuevos migrantes se involucraban en la vida de los viejos vecinos, sobre todo en las fiestas patronales, como la procesión de la Virgen del Carmen, en las parrilladas de gato y en las festividades culturales de cada región, 
pero también en otras actividades ilegales que se consolidaron como "negocios" de la zona, especialmente de prostitución y venta de PVC. Durante la hiperinflación originada por el gobierno de Alan García Pérez, la industria nacional decayó críticamente y la instalación de mercados informales de abastecimiento de productos básicos fue una alternativa importante de subsistencia para estos barrios.

Ricardo Belmont, alcalde de la ciudad entre 1990 y 1995, traslada a los comerciantes agrupados al margen derecho de la Av. Argentina, en las seis cuadras de la berma central, lo que daría la supuesta apariencia de una pequeña isla comercial limpia y ordenada: "Las Malvinas". Los comerciantes que lograron alquilar los puestos de cuatro metros cuadrados, creados por la Municipalidad, se establecieron como pequeño mercado minorista de verduras y abarrotes, y como un bazar para los vecinos de los alrededores. Los puestos eran de fierro y se protegían con candados. Otra red de fierro enorme y con otros inmensos candados protegía toda la isla, que no era sino la berma central de la avenida. Los otrora comerciantes ambulantes aprovecharon la situación de los nuevos migrantes para hacerlos trabajar en terribles condiciones: aquellos "ayudaban" a los nuevos con alguna propina, pues -según los comerciantes- no era propiamente un trabajo cargar bultos, acomodar mercancía, vigilar los puestos, vender (lo que se llamaba "derecho de piso"). El trato al nuevo "migrante" era cada vez más duro por parte del antiguo migrante. Los comerciantes de PVC y otros negocios ilícitos, como prostíbulos, también crecieron y aumentaron su poder en la zona, aprovechándose de la precarización y del desempleo de la década.

Alberto Andrade, alcalde de Lima entre 1996 y 2002, planteó que los objetivos de su gestión serían el embellecimiento de la ciudad, el desalojo de ambulantes del centro histórico y priorizar una idea de belleza y orden típicos de la Lima colonial. Los ambulantes que trabajaban en distintos puntos del Centro debían ser desalojados y Las Malvinas podría convertirse en un área comercial que "acogiera" a todos los comerciantes informales. Así, muchos comerciantes fueron trasladados a la "isla", pero la zona no mejoró las condiciones; por el contrario, se intensificaron las falencias urbanísticas: no había recojo de basura, incrementaron los problemas de acceso al agua y al desagüe, la 
energía eléctrica era tomada de los postes de luz y había más inseguridad. Años después, Andrade planteó el desalojo de Las Malvinas y exigió que los comerciantes alquilen o compren galerías (espacios construidos en las antiguas fábricas sin funcionamiento que habían sido cerradas por la crisis económica), exigencia que fue rechazada por los comerciantes que se habían sentido desalojados todo el tiempo, a los que se les cobraba un impuesto por su instalación y no se le ofrecía ningún beneficio. En resumen, sentían que su trabajo no era reconocido por el Estado como tal y que, además, eran considerados como un problema social que debería combatirse.

Durante estos años, la isla vive en pugna por la defensa del derecho al trabajo y por la falta de reconocimiento de entidades del Estado, que intentaba ubicar en Las Malvinas el microcomercio nacido del comercio ambulatorio. El conflicto social provocaba que el barrio fuera percibido como muy peligroso, incluso para los antiguos vecinos, pues su seguridad dependía de las relaciones que se establecieran entre los dueños de las galerías y los comerciantes, lo que también dio paso al tráfico de tierras, a la venta de objetos robados y a una variedad de comerciantes ambulantes que difícilmente se podía organizar en el espacio. Todo estaba presente en el lugar: papa con huevo junto a antigüedades y celulares robados, ropa interior de Gamarra junto a ropa con etiqueta de Saga Falabella, venta de armas, juguetes y herramientas de construcción junto a platos típicos; no había manejo ni control de la basura y aumentó el crimen organizado. No obstante, esta lógica identitaria compartida que se había construido en torno al progreso social permitió que entre los comerciantes existan redes y organizaciones de defensa del trabajo informal.

Si bien, en el transcurso de los años, diversas instituciones ofrecieron créditos en beneficio del crecimiento de los comerciantes, pocas normas de control se establecieron en Las Malvinas, porque la zona era percibida como el lugar donde terminaba el Centro Histórico y que alojaba la informalidad y el caos. De este modo, Las Malvinas se convirtieron en el espacio donde el progreso económico y la ilegalidad se hermanaban, puesto que la esperanza por contar con oportunidades económicas y sociales se mezclaba con la permisividad de la esclavitud, la pobreza y la alta tolerancia a prácticas injustas. 


\section{Injusticias persistentes: comprensión, poder y mercado}

Pasaron dos meses y nadie salió a tomar las calles para protestar por la situación de las víctimas de Las Malvinas. Sin embargo, la esclavitud en la que se encontraban Jovy y Jorge no era un hecho aislado, sino que tenía una historia de décadas, en las que el progreso económico, la informalidad y el empleo precario se entrecruzaban como hilos de un mismo tejido, que describe la crónica del periodista Calsina (2019). Formalmente, en nuestra época, podríamos afirmar que la esclavitud es retrógrada, discriminadora, injusta e inmoral; sin embargo, existe y convivimos con ella, lo que nos hace reflexionar que aceptamos vivir en una contradicción moral: la esclavitud es mala, pero forma parte del desarrollo económico. Como explica la Organización Internacional del Trabajo (OIT, en adelante) en un estudio de 2015, la esclavitud moderna es el tercer delito más lucrativo en el mundo y, en América, el Perú ocupa el tercer lugar luego de México y Colombia (OIT, 2015). Durante años, en emporios comerciales informales, como Las Malvinas, La Parada y Gamarra, se han denunciado situaciones laborales esclavizantes por los propios trabajadores, pero poco o nada se ha hecho para atender estas denuncias.

\subsection{Fricker: el déficit de credibilidad}

Cosamalón indica tres interpretaciones del trabajo informal. Primero, el enfoque estructuralista que fija la relación entre la producción capitalista y el surgimiento de la economía informal, considerando a esta última como un producto anómalo y secreto del sistema (2018: 36). Segundo, el enfoque neoinstitucional que critica la injerencia del Estado en la economía, lo cual ha impedido valorar la autogestión de los comerciantes informales como parte del desarrollo de un mercado neoliberal (2018: 38). Tercero, el enfoque integral que aborda la informalidad desde distintas dimensiones (sociales, políticas, económicas) y apela a un continuum entre la economía formal e informal (2018: 36). Habría que preguntarse, desde los alcances de esta tercera interpretación, qué posibilidades analíticas brinda poner "entre paréntesis" la disyunción informalidad-formalidad para pensar 
qué subsiste entre formas sociales de desarrollo económico y poder social.

Según Michael Polanyi, en la ciencia, "conocemos más de lo que decimos" (2009: 4), es decir, existe una dimensión tácita del conocimiento, un conjunto de elementos implícitos en las prácticas del conocimiento sin los cuales este no existiría; hacemos uso de la dimensión tácita del conocimiento sin asumirla explícitamente. La intencionalidad corporal es un ejemplo: nos movemos, usamos utensilios puestos en nuestra cultura, pero este saber del cuerpo es preconsciente y antepredicativo. De este modo, Polanyi advierte la existencia de un conocimiento indecible, implícito, preyoico (2009: 12), que está presente en las actividades del conocedor y se filtra en su práctica científica. El conocimiento implícito no forma parte de nuestro discurso, es acrítico e inarticulado. No obstante, es posible acceder a él, evidenciarlo a través de una capacidad crítica que entrevea ciertos patrones tácitos que han operado sistemáticamente.

En la misma línea que Polanyi, Miranda Fricker parte de una idea intuitiva del poder social como la capacidad socialmente situada de un agente para controlar las acciones de otro. Dicha capacidad puede ejercerse activa o pasivamente por los agentes, sin que ellos reconozcan con claridad los componentes significantes que se encuentran detrás del ejercicio del poder (Fricker, 2007: 13). La autora se interesa por este "poder identitario" que aparece como pasivo, estructural, tácito y que no tiene la necesidad de ser deliberado para ser ejecutado. ¿Qué de particular tiene este poder? Es un poder primario, que nace del imaginario colectivo de las identidades de los grupos sociales y se manifiesta cuando hacemos juicios de credibilidad usando intuitivamente estereotipos que se han formado en nuestro imaginario colectivo. Fricker brinda un ejemplo: creemos lo que afirma un médico sobre una enfermedad, porque asumimos que él está en condiciones de responder, lo escuchamos otorgándole confianza epistémica (2007: 31 ), porque partimos de la premisa de que el médico es especialista en su materia. Desde esta dimensión tácita, el estereotipo es un recurso neutral, ya que lo utilizamos para fiarnos de lo que otro afirma. Por eso, piensa Fricker, los estereotipos funcionan como compromisos afectivos 
para dar credibilidad al conocimiento del hablante; ellos tienen un uso disfuncional, puesto que los usamos para otorgar exceso o déficit de credibilidad al hablante. Por un lado, el exceso de credibilidad es el caso del médico mencionado anteriormente: es probable que no sea especialista en la enfermedad, pero su investidura de médico en el imaginario colectivo permite que le brindemos confianza a su testimonio. Por otro lado, un déficit de credibilidad se da cuando el uso de los estereotipos puede ser perjudicial para el hablante. El ejemplo de Fricker es el siguiente: un policía no cree el testimonio de una persona, porque es afrodescendiente. En este caso, el oyente debe tener la responsabilidad y la capacidad suficientes para neutralizar sus estereotipos negativos e intentar que estos no perjudiquen la confianza epistémica de la comunicación.

¿Qué ocurre si no se neutralizan los prejuicios? Para Fricker, se produce una injusticia testimonial. Esta aparece cuando el oyente, a pesar de saber que el estereotipo no es fiable, lo sigue considerando para emitir juicios de credibilidad, porque hay una "fuerte afección" del oyente con este estereotipo. En este caso, los estereotipos han dejado de ser creencias del imaginario colectivo y se han convertido en prejuicios, a saber, afectos o creencias que se mantienen, a pesar de que cuentan con toda la evidencia para no ser considerados como verdaderos. Entonces, el prejuicio identitario opera de manera perjudicial y desventajosa para el hablante, porque genera un "déficit de credibilidad", es decir, agravia (socava, menosprecia) al hablante en su calidad de interlocutor y conocedor.

Sería pertinente preguntarse si, al intentar estudiar el comercio informal, estaríamos manejándonos por prejuicios epistémicos; en otras palabras, si los argumentos que deslegitiman la informalidad como negativa olvidan que esta parte de un trasfondo histórico estructural de discriminación y, al mismo tiempo, está ligada al mercado formal, que se vincula con los espacios periféricos (sin normas ni seguimiento) para desarrollarse. En síntesis, deberíamos preguntarnos si se estaría anteponiendo prejuicios identitarios que obstaculizan una comprensión más amplia del fenómeno informal de sus trabajadores y de sus víctimas en el espacio laboral. 
En la descripción histórica sobre Las Malvinas, hemos llegado a la conclusión, de que el poder identitario puede producir formas de injusticia estructural, en palabras de Fricker. Un migrante que llega con el sueño de mejorar su calidad de vida y que trabaja como ambulante suele representar, para la sociedad limeña, la versión periférica del comercio e incluso es considerado como un obstáculo para el "verdadero" desarrollo económico, regido por las normas del mercado capitalista formal. Específicamente, en Las Malvinas, se mezclan otros componentes de injusticia estructural: el comerciante es pobre, no es limeño y vive en zonas de poco control y regulación; ergo, es identificado o etiquetado como "peligro social". Todo ello acentúa más los prejuicios $\mathrm{y}$, por lo tanto, las formas posibles en las que el Estado puede enfrentar el problema. Así, se establece un tejido de prejuicios identitarios que merman sobre el grupo social excluido y menospreciado, que no permiten hacer evidente una situación de injusticia que nace de otras formas de exclusión. El déficit de credibilidad opera dańando al grupo social, porque este pierde credibilidad en sus acciones y testimonios, y lo aparta de la institucionalidad y lo desvincula del Estado, que debería proteger a todos los grupos sociales por igual. Asimismo, en el ámbito académico, el grupo social suele ser etiquetado al pensar sus prácticas como negativas, en tanto se oponen a una visión de desarrollo formal capitalista, que suele fragmentar las dimensiones del desarrollo económico. Por ejemplo, los funcionarios municipales hacen inspecciones en Las Malvinas, registran y evalúan el orden del espacio; la Sunat analiza el registro de impuestos a través de boletas y facturas, pero poco importa en este proceso el desarrollo regular de las microempresas, el cuidado de los derechos laborales (operativos esporádicos del Ministerio de Trabajo y Promoción del Empleo) y la relación que se establece entre el trabajo y el progreso social; es decir, el déficit de credibilidad actúa impidiendo hacer un análisis integral y medular del problema de injusticia. 


\subsection{Honneth: el mercado capitalista como patología institucionalizada}

A diferencia de Fricker, que pone el acento en un conocimiento tácito basado en estereotipos y su uso disfuncional, Axel Honneth entiende el conocimiento tácito como fuente de eticidad y progreso. El autor piensa las relaciones sociales identificando patologías, es decir, déficits que impiden la autorrealización colectiva o la falta de racionalización que bloquea el desarrollo intersubjetivo (o el bien común) de los miembros de una sociedad (2009: 32). El autor centra la atención en los déficits patológicos de la economía, pues cree que el capitalismo es responsable de muchas patologías. Retomando las ideas de Lukács, Honneth señala lo siguiente:

En una terminología más cercana a nuestras representaciones actuales, el resultado del análisis de Lukács se podría exponer así: con el capitalismo ha llegado a prevalecer una forma de praxis que obliga a ser indiferente a los aspectos de valor de otros seres humanos; en lugar de relacionarse entre sí reconociéndose, los sujetos se perciben como objetos que hay que conocer según los intereses propios. En todo caso, es este diagnóstico de Lukács el que le proporciona a la Teoría Crítica el marco categorial en el que puede hablarse de una interrupción o parcialización del proceso de realización de la razón. (2009: 42)

Según Honneth, la mecanización, la división del trabajo, el intercambio de mercancías y la racionalidad de fines han generado una forma de organización social que bloquea la disposición para una praxis colectiva, más allá de un plano jurídico o de un razonamiento instrumental (2014: 123). En efecto, la expansión del mercado se produjo cuando se hizo un uso generalizado del dinero, cuya regulación de las relaciones entre los participantes (trabajadores, consumidores, empresarios) se dio como transacciones. En el momento de expansión, había un interés "implícito" proyectado a la construcción de una sociedad edificada sobre un homo economicus libre, sin intervención del Estado (2014: 234-237). No obstante, ante dicha expansión, hubo una 
intranquilidad intelectual: varios autores mostraron su preocupación por encontrar la legitimidad a la nueva esfera de relaciones mercantiles y le pusieron, al mismo tiempo, límites para promover de manera global la autorrealización de todos los participantes. Hegel y Durkheim pensaron-según Honneth- que era necesario incluir reglas de acción del mercado que no fueran contractuales, pero sí vinculantes, es decir, pensar en una concepción del mercado como esfera de libertad social, que considere la autorrealización de los individuos y la solidaridad entre ellos (2014: 241). No obstante, a partir de 1917, con la Revolución rusa, se pierde el interés público de justicia por las normas del mercado y se entra en una fase de fuerzas de poder: por un lado, los movimientos sociales esporádicos retoman la preocupación histórica de Hegel y Durkheim en torno a la protección del consumidor, los derechos laborales, el acceso al trabajo, la propiedad intelectual, etc., y, por otro lado, el mercado se separa de un interés político (y conserva solo dos valores: la propiedad privada y la protección al fraude), para crecer de una manera más independiente. Se crea, así, una nueva forma de operar económicamente: participar de los problemas sociales denunciados por los movimientos, siempre y cuando se logre un mayor número de consumidores. Entonces, para no quebrar las normas del capitalismo y dar respuesta a los movimientos sociales, se crean programas sociales o se atienden de manera particular las demandas, a lo que Honneth llama "economía de mercado desinsertada" (2014: 247). De este modo, explica el autor, se ha instaurado la patología, porque los actores del mercado no se percatan de cómo, dentro de él, conciben su libertad social fragmentada.

En el Perú, la construcción histórica del mercado (y su negación en la patología del consumo) mezcla injusticias históricas (por raza, género, procedencia, idioma, etc.). Mientras las personas sean más marginadas socialmente y tengan menor acceso a servicios impartidos por el Estado, serán más excluidas también de la lógica del mercado. El capitalismo afianza sus patologías mediante la lógica del consumo y excluye del mercado a los trabajadores de Las Malvinas, campo ferial que reúne todos los prejuicios, lo que no permite involucrarlos en las relaciones del mercado y la cultura. 
Honneth se pregunta si se puede superar los principios del capitalismo e ir más allá de una racionalidad restringida o "reificante", es decir, si es plausible explicitar las condiciones que permitan llegar a un conocimiento de la praxis colectiva. Honneth cree necesario partir del malestar de la praxis "deformada" (el sufrimiento, la lesión -tal como lo entendía Freud- como la sensación de obstruir las facultades del yo) como principio de apelación para la crítica. El malestar es el punto arquimédico en el que se concentran el carácter práctico y teórico. ¿Quién podría personificar o reconocer el malestar? Según el autor, son los sujetos que perciben los malestares, que sienten el deseo de transformación, porque observan que el sistema económico no favorece una igualdad de oportunidades para la autorrealización. Fricker compartiría la misma perspectiva, y priorizaría, en la injusticia testimonial, la situación de menosprecio del hablante, que ha sido silenciado y tiene un privilegio epistémico, porque, al no ser reconocido por su capacidad de dar testimonio, experimenta el menosprecio y, con ello, la posibilidad de saber que se está produciendo una injusticia. En resumen, Honneth y Fricker creen que el sujeto que vive y siente el menosprecio tiene la posibilidad de enseñarle a la sociedad algo que esta ignora y de darle un carácter cognitivo a esa experiencia.

Honneth cree que el privilegio de la indignación puede estar personificado en los colectivos sociales, ya que estos hacen explícita su indignación desde la manifestación y la rebelión. Las luchas proletarias de los ańos veinte, las revueltas obreras, Mayo del 68, etc., son episodios esporádicos de actores colectivos, guiados por intereses morales que quieren dar validez a los principios subyacentes de la eticidad (Honneth, 2014: 278). Mientras Fricker identifica al sujeto que vive el menosprecio como agente para la explicitación, Honneth identifica a los sujetos sensibles, agrupados para denunciar la injusticia social.

\section{Las Malvinas: injusticia revertida en conocimiento}

¿Con qué elementos cuentan los obreros de Las Malvinas -los jorges y yovys- para superar la injusticia, luchar contra ella y reconocer los prejuicios que se le atribuyen como parte de un imaginario colectivo? 
¿Con qué elementos cuentan los funcionarios públicos y la sociedad civil para transformar su propia visión de una realidad informal e injusta, y encontrar nuevas alternativas que superen la dicotomía inclusiónexclusión social? Fricker define la culpabilidad epistémica cuando el sujeto tiene toda la evidencia necesaria para cambiar su prejuicio, pero se resiste a reconocerlo como tal, porque se produce en él una "inversión afectiva" (35). Asimismo, la autora la denomina mala suerte epistémica cuando los patrones del sujeto se ven profundamente influenciados por los prejuicios de su tiempo, en cuyo caso el oyente o el hablante necesitaría un "carácter epistémico excepcional" para superar los prejuicios. Por ejemplo, en el siglo XVI, no había inconveniente en ser amables con los hacendados esclavistas, porque no se contaba con todos los elementos para reconocer la esclavitud como injusticia, a menos que quien tuviese una capacidad excepcional mayor pudiese observar esta situación como injusta. En este caso, el oyente y el hablante podrían encontrarse en una situación de "mala suerte", y -por ende- los agentes no pueden ser juzgados como culpables, aunque históricamente sí pueden causar una decepción moral y epistémica (Fricker, 103). Para superar la mala suerte y no caer en la culpa, Fricker apela a la formación de oyentes socialmente situados y socialmente virtuosos. En términos aristotélicos, significaría habituarse a reconocer y neutralizar los prejuicios sociales. La autora propone una virtud hibrida, descrita como una "sensibilidad racional", con las siguientes características:

- Para una justicia testimonial, el modelo de juicio debe ser la percepción y no la inferencia.

- El juicio no es codificable, es decir, no se aplica a ciertas normas o reglas fijas en la estructura social. El juicio es flexible.

- El juicio contiene en sí un aspecto emocional (motivador) y un aspecto cognitivo (que brinda razones para que el agente actúe).

Para que el oyente logre juicios "híbridos", debe formar su sensibilidad testimonial en la experiencia, vale decir, en la repetición de una acción, como escuchar al otro empáticamente para interpretarlo. 
Los juicios híbridos no se forman en una aplicación de principios, sino en una amplia experiencia de escuchar y juzgar testimonios. Como explica Fricker, el oyente virtuoso es alguien cuyo patrón de juicios de credibilidad espontáneos cambia a la luz de las correcciones de prejuicios pasados y retiene una capacidad de respuesta (Fricker, 97). Es importante resaltar que no se trata de un sujeto en alerta irrefleja, flexible de modificar sus ideas y reconocer hasta qué punto debe o no confiar. Así, el oyente virtuoso se compromete empáticamente y otorga la confianza epistémica a su interlocutor, cuyo objetivo será permitir el desarrollo epistémico y ético de la comunicación, y distanciarse de las injusticias, a través de la neutralización de prejuicios. Esto no es compatible con Honneth, quien explica que los movimientos sociales inician su irrupción contra el sistema articulando, en la manifestación misma, lo cognitivo y emocional. Mientras que Fricker explica la virtud híbrida desde una agencia subjetiva, Honneth piensa en una agencia colectiva.

\section{Conclusión}

Guiados por la reflexión de Fricker y Honneth, hemos descrito cómo, para ambos autores, los sujetos que pertenecen a una estructura social tienen un lugar desde el que se puede desarrollar una experiencia de alerta irrefleja, que promueva los juicios de credibilidad con cualquier hablante. Así sea con la confianza epistémica o con la crítica social, los sujetos se hacen responsables de sus formas de relación social y, al mismo tiempo, de su autorrealización individual, aunque, desde puntos de partida distintos, para Fricker y Honneth, la reflexión crítica y ética se genera cuando las experiencias tradicionales de los sujetos entran en tensión. Debemos preguntarnos también lo siguiente: ¡los obreros esclavizados tienen alternativas para revertir sus injusticias? En su cuenta de Facebook, Jovi Herrera, natural de Huánuco, escribía el 29 de noviembre de 2016: "No tengo miedo a la muerte, solo tengo miedo a que me olviden”. (Herrera, 2016). Ese miedo, pienso, aparece como un malestar natural de ciertos escenarios sociales y es un malestar de la injusticia histórica que hemos vivido personas en zonas como 
Las Malvinas. Desde esa experiencia, se toma conciencia de que la injusticia que se olvida regresa multiplicada. El saberse perteneciente a un escenario de injusticia produce miedo de ser víctima posible de una nueva injusticia.

Muchos jóvenes del país seguirán llegando a Las Malvinas, haciendo señas con fluorescentes para sobrevivir y tratar de conseguir un porvenir; ellos aprenderán a armar cajas de luz, a combinar pinturas, a reparar bombas de agua. Algunos podrán, con suerte, salir y lograr construir vidas elegidas, después de haber invertido mucho dinero, tiempo y esfuerzo, aunque vivirán con la sensación permanente de estar anímicamente "pegados" con alfileres, a punto de desplomarse. Esos días, no menos importantes ni despreciables, uno se siente capaz de tocar con cariño sus propias costuras, puede reconocer ese vínculo intersubjetivo que lo ata a su situación inmediata y reconocer cómo a través de su vida los malestares sociales nos coconstituyen. Este salto, privilegiado de ponerse a pensar en soluciones colectivas para los que vivimos este tipo de experiencias pueda acercar la vida de un trabajador informal a los intereses académicos por la injusticia que suponga, en ambos casos, neutralizar nuestros propios prejuicios sociales. Vale la pena recordar en este punto las palabras del sacerdote Huberth Lansiers, capellán de las cárceles en el periodo del Conflicto Armado Interno: "Aquel que no tiene la experiencia no entenderá la palabra y aquel que tiene la experiencia no necesita discursos" (33).

\section{Bibliografía}

Calsina Calixto, Gian (2019). Las Malvinas: los sobrevivientes del incendio. Informalidad, desigualdady otras tragedias. Lima: Fondo Editorial de la Universidad Peruana de Ciencias Aplicadas.

Contreras, Carlos y Marcos Cueto (2007). Historia del Perú contemporáneo. Desde la lucha por la independeincia hasta el presente. Lima: Instituto de Estudios Peruanos. 
Cosamalón, Jesús (2018). El apocalipsis a la vuelta de la esquina. Lima, la crisis y sus supervivientes (1980-2000). Lima: Fondo Editorial de la Pontificia Universidad Católica del Perú.

Diario Gestión (2017). "Conglomerado Las Malvinas tiene pérdidas diarias por más de US \$2 millones”. Recuperado de: <https:// gestion.pe/economia/empresas/conglomerado-malvinasperdidas-diarias-us-2-millones-138007>

Fricker, Miranda (2007). Epistemic Injustice. New York: Oxford University.

Granados, Miriam (1997). Actores sociales de la ciudad: el caso de los vendedores ambulantes de Lima. Ginebra: Instituto de Estudios de Desarrollo.

Guzmán, Iveth (2017). "Las Malvinas: se incrementa a 89 las personas heridas por el incendio. En: Diario Correo. Recuperado de: $<$ https://diariocorreo.pe/peru/incendio-de-grandes-proporcionesconsume-almacen-al-frente-de-las-malvinas-757531/>

Honneth, Axel (2009). Patologías de la razón. Historia y actualidad de la Teoría Critica. Buenos Aires, Katz. -(2014). El derecho a la libertad, Buenos Aires, Katz.

Grompone, Romeo (1999). Las nuevas reglas de juego. Transformaciones sociales, culturales y politicas en Lima. Lima: Instituto de Estudios Peruanos.

Matos Mar, José (1984). Desborde popular y crisis del Estado. Lima: Instituto de Estudios Peruanos.

(1991). "El sector informal: sociedad y cultura". En: Alejandro Toledo y Alain Chalat (eds.), Las otras caras de la sociedad informal. Una visión multidisciplinaria Lima: ESAN e IDE. pp. 135-154. 
Katherine Mansilla Torres

Organización Internacional del Trabajo (2015). Formalizando la informalidad juvenil: experiencias innovadoras en América Latina y el Caribe. Lima: OIT. Recuperado de: <https://www.ilo.org/ wcmsp5/groups/public/---americas/---ro-lima/documents/ publication/wcms_359270.pdf>

Polanyi, Michael (2009). The Tacit Dimension, Chicago: University of Chicago Press. 